\title{
Utilization Pattern of Anti-Depressants at a Tertiary Hospital in Oman: A Retrospective Analysis
}

\section{Mohammed Al Za'abi ${ }^{*}$, Asaad S. Al Jabri and Jabran K. Al Bartamani}

Department of Pharmacology \& Clinical Pharmacy, College of Medicine \& Health Sciences, Sultan Qaboos University, Oman

"Corresponding author: Mohammed Al Za'abi, Department of Pharmacology and Clinical Pharmacy, College of Medicine and Health Sciences, Sultan Qaboos University, P. O. Box 115 Al Khod, Postal code 123, Oman, Tel/Fax: +968 2414 1107; E-mail: zaabi@squ.edu.om

Received Date: September 10, 2014, Accepted Date: September 23, 2014, Published Date: September 30, 2014

Copyright: @ 2014, Mohammed Al Za'abi et al., This is an open-access article distributed under the terms of the Creative Commons Attribution License, which permits unrestricted use, distribution, and reproduction in any medium, provided the original author and source are credited.

\begin{abstract}
Introduction: Antidepressants play a major role in managing depression and other conditions. The use of various classes of antidepressants varies from a country to another but information about the use of these agents in the developing countries is scarce.
\end{abstract}

Objective: To assess the use of different classes of antidepressant medications in a tertiary hospital in Oman.

Method: Data over four month period (January to April 2013) were retrieved retrospectively after obtaining ethical approval.

Results: A total number of 1416 prescriptions were analyzed. Of these $880(62.1 \%)$ were for females and 536 (37.9\%) were for males. Tricyclic antidepressant (TCAs), selective serotonin reuptake inhibitors (SSRIs), serotonin/ norepinephrine reuptake inhibitors (SNRIs) and mirtazapine accounted for 34.6\%, 32.1\%, 13.3\% and 19.9\% of prescriptions, respectively. Monotherapy accounted for $89.3 \%$ of prescriptions. The most used single antidepressant drug was amitriptyline $(28.5 \%)$ followed by mirtazapine $(19.9 \%)$ and paroxetine $(17.9 \%)$. SSRIs, SNRIs and mirtazapine were mainly used for psychiatric conditions in $82.2 \%, 73.0 \%$ and $68.8 \%$ of the cases, respectively, while TCAs were mainly indicated $(63.7 \%)$ for non-psychiatric conditions.

Conclusion: Monotherapy antidepressant is the preferred mode of therapy with SSRIs and mirtazapine as first line therapy for depression which is consistent with therapeutic guidelines recommendations.

Keywords: Antidepressants; Amitriptyline; Mirtazapine; Depression

\section{Introduction}

Depression, a mood disorder, is a highly prevalent disease that is expected to be the second largest source of global burden of diseases by the year 2020 [1,2]. Currently, the World Health Organization (WHO) list depression as the fourth leading cause of disability overtaking chronic diseases such as hypertension and diabetes [3]. It is also considered as the leading cause of premature death and disability among people from 18-60 years of age [4]. The health risks associated with depression demand cost-effective therapies. In this regards, antidepressant drugs considered the first line and the most widely used form of therapy for depression [5].

Antidepressant drugs have undergone remarkable evolution since their discovery in 1950s. This evolution has also lead to a continues changes in their prescribing patterns where the conventional agents like tricyclic antidepressants (TCA), and monoamine oxidase inhibitors (MAOI), selective serotonin reuptake inhibitors (SSRIs) being replaced by newer antidepressants like serotonin/ norepinephrine reuptake inhibitors (SNRIs), tetracyclic antidepressants and others. The trends in the usage of these agents, influenced by various factors, vary from a country to another [6-8].

In Oman and with the slow move towards modernization phase, depression is expected to increase rapidly and hence the prescribing of antidepressant drugs. WHO estimates that the people suffering from mental illnesses in Oman will rise from $1 \%$ (2006) to $5 \%$ by the year 2020 [3]. However, there are yet no solid epidemiological reports on the different types of mental illnesses especially depression in Oman or utilization patterns of psychopharmacological agents such as antidepressants. Therefore, the aim of this study is to assess the use of different classes of antidepressants in Oman by describing the clinical patterns of use of antidepressant medications in a tertiary hospital, Sultan Qaboos University Hospital (SQUH), in the four months period of January to April 2013.

\section{Methods}

The study was retrospective in nature where antidepressant drugs prescriptions for patient's $\geq 18$ years of age attending SQUH, a tertiary health care facility in Oman, were reviewed. The information was retrieved from electronic patient records "TrakCare", the Hospital Information System, in the period of January to April 2013. A data collection sheet was designed and used to gather information about patients' demographic characteristics such as sex, age and weight; disease data such as type of disease, co-morbidities and duration and medications data such as type, concomitant drugs and recorded side effects. Diseases were classified according to the Diagnostic and Statistical Manual of Mental Disorders (DSM-5) guide [9]. An ethical approval was obtained from Sultan Qaboos University Medical Ethics Committee before commencing the study. 
Citation: Al Za'abi M, Al Jabri AS, Al Bartamani KJ (2014) Utilization Pattern of Anti-Depressants at a Tertiary Hospital in Oman: A Retrospective

Page 2 of 4

Statistical Package of Social Sciences version 15 (SPSS, Inc., expressed as means, percentages and percentiles depending on their Chicago, IL, USA) was used for data entry and analysis. Results were distributions and tables were used to illustrate the data.

\begin{tabular}{|c|c|c|c|c|c|c|c|c|c|c|c|}
\hline \multirow[t]{3}{*}{ Age (Years) } & & \multicolumn{2}{|c|}{$18-29$} & \multicolumn{2}{|c|}{$30-40$} & \multicolumn{2}{|c|}{$41-50$} & \multicolumn{2}{|c|}{$51-60$} & \multicolumn{2}{|c|}{$>60$} \\
\hline & \multirow[t]{2}{*}{$\mathrm{N}$} & \multicolumn{2}{|c|}{210} & \multicolumn{2}{|c|}{331} & \multicolumn{2}{|c|}{346} & \multicolumn{2}{|c|}{273} & \multicolumn{2}{|c|}{256} \\
\hline & & M & $\mathrm{F}$ & M & $\mathrm{F}$ & M & $\mathrm{F}$ & M & $\mathrm{F}$ & M & $\mathrm{F}$ \\
\hline Paroxetine & 254 & 30 & 29 & 41 & 41 & 21 & 46 & 15 & 19 & 5 & 7 \\
\hline Fluoxetine & 201 & 22 & 22 & 32 & 29 & 15 & 21 & 12 & 26 & 7 & 15 \\
\hline Venlafaxine & 112 & 9 & 9 & 16 & 14 & 12 & 25 & 3 & 11 & 4 & 9 \\
\hline Duloxetine & 77 & 3 & 1 & 6 & 10 & 8 & 11 & 8 & 16 & 6 & 8 \\
\hline Amitriptyline & 403 & 18 & 18 & 27 & 53 & 25 & 81 & 20 & 70 & 26 & 65 \\
\hline Clomipramine & 44 & 9 & 1 & 11 & 4 & 4 & 5 & 1 & 5 & 1 & 3 \\
\hline Imipramine & 43 & 5 & 13 & - & 7 & 3 & 5 & - & 5 & - & 5 \\
\hline Mirtazapine & 282 & 7 & 14 & 20 & 20 & 26 & 38 & 24 & 38 & 34 & 61 \\
\hline Total & 1416 & 103 & 107 & 153 & 178 & 114 & 232 & 83 & 190 & 83 & 173 \\
\hline
\end{tabular}

Table 1: Age groups and gender distribution of antidepressant prescriptions

\begin{tabular}{|c|c|c|c|c|c|c|c|c|c|c|c|c|c|c|c|c|c|}
\hline \multirow[t]{2}{*}{ Condition } & \multirow[t]{2}{*}{$\mathrm{N}$} & \multicolumn{2}{|c|}{ Paroxetine } & \multicolumn{2}{|c|}{ Fluoxetine } & \multicolumn{2}{|c|}{ Venlafaxine } & \multicolumn{2}{|c|}{ Duloxetine } & \multicolumn{2}{|c|}{ Amitriptyline } & \multicolumn{2}{|c|}{$\begin{array}{l}\text { Clomipram } \\
\text { ine }\end{array}$} & \multicolumn{2}{|c|}{$\begin{array}{l}\text { Imiprami } \\
\text { ne }\end{array}$} & \multicolumn{2}{|c|}{ Mirtazapine } \\
\hline & & M & $\mathrm{F}$ & M & $\mathrm{F}$ & M & $\mathrm{F}$ & M & $\mathrm{F}$ & M & $\mathrm{F}$ & M & $\mathrm{F}$ & M & $\mathrm{F}$ & M & $\mathrm{F}$ \\
\hline Depressive disorder & 381 & 18 & 43 & 27 & 37 & 12 & 31 & 7 & 13 & 19 & 44 & 4 & 5 & 1 & 7 & 44 & 69 \\
\hline $\begin{array}{lll}\text { Mixed Anxiety } & \text { and } \\
\text { Depressive disorder } & \end{array}$ & 88 & 10 & 16 & 4 & 9 & 5 & 4 & 2 & 6 & 4 & 10 & 1 & 2 & - & 2 & 3 & 10 \\
\hline $\begin{array}{l}\text { Schizophrenia with post } \\
\text { schizophrenic depression }\end{array}$ & 64 & 7 & 8 & 9 & 6 & 2 & 2 & 1 & 1 & 2 & 6 & 3 & - & 1 & 3 & 7 & 6 \\
\hline 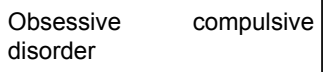 & 83 & 11 & 20 & 13 & 11 & 2 & 6 & 2 & 1 & 2 & 1 & 6 & 3 & - & - & 1 & 4 \\
\hline Social phobia & 40 & 18 & 3 & 5 & 1 & 4 & - & 2 & - & - & - & 4 & 1 & - & 1 & 1 & \\
\hline Panic disorder & 24 & 3 & 7 & 2 & 2 & & 3 & & 1 & - & - & 1 & 1 & - & - & 1 & 3 \\
\hline Other Anxiety disorders & 109 & 22 & 21 & 7 & 6 & 8 & 6 & 2 & - & 6 & 8 & 3 & 2 & - & 2 & 10 & 6 \\
\hline $\begin{array}{l}\text { Acute and Transient } \\
\text { psychotic disorder }\end{array}$ & 21 & 4 & 1 & 1 & 3 & 1 & 2 & - & - & 2 & - & - & - & - & 1 & 3 & 3 \\
\hline Hyperkinetic disorder & 5 & - & - & 1 & - & - & - & - & - & 2 & 1 & - & - & 1 & - & & - \\
\hline Bipolar Affective Disorder & 40 & 2 & 2 & 2 & 5 & 3 & 2 & 1 & 1 & 1 & 3 & - & 1 & 1 & - & 5 & 11 \\
\hline Somatization Disorder & 29 & 2 & 2 & 1 & 1 & - & 2 & 1 & 3 & 2 & 8 & - & - & - & - & 2 & 5 \\
\hline Others & 533 & 15 & 19 & 15 & 32 & 7 & 10 & 13 & 21 & 76 & 206 & 4 & 3 & 4 & $\begin{array}{l}1 \\
9\end{array}$ & 34 & 54 \\
\hline Total & 1416 & 112 & 142 & 88 & 113 & 44 & 68 & 31 & 46 & 116 & 287 & 26 & 18 & 8 & $\begin{array}{l}3 \\
5\end{array}$ & 111 & 171 \\
\hline
\end{tabular}

Table 2: Indication for the use of antidepressant drugs 
Page 3 of 4

\section{Results}

A total number of 1416prescriptions were analyzed. Of these 880 $(62.1 \%)$ were for females and $536(37.9 \%)$ were for males. The age group 41-50 years constitutes $24.4 \%$ of all prescription followed by $23.4 \%$ and $19.3 \%$ for the age groups $30-40$ and 51-60 years, respectively (Table 1).

\begin{tabular}{|l|l|l|l|}
\hline & N & M & F \\
\hline Headache & 84 & 16 & 68 \\
\hline Neuropathic pain & 54 & 13 & 41 \\
\hline Diabetes/Hypertension related neuro/nephropathies & 59 & 26 & 33 \\
\hline Alzheimer & 32 & 32 \\
\hline Urinary incontinence & 21 & 21 \\
\hline Bowel diseases & 28 & 10 & 18 \\
\hline Malignancy & 18 & 18 \\
\hline Post-operative & 12 & 12 \\
\hline Mental growth retardation & 8 & 15 & 8 \\
\hline Nephropathies & 15 & 15 \\
\hline Epilepsy & 5 & 5 & 11 \\
\hline Parkinson & 6 & 11 & \\
\hline Dementia & 12 & 5 & \\
\hline Insomnia and other sleep disorders & 5 & \\
\hline Others & & \\
\hline
\end{tabular}

Table 3: Non psychiatric indication of antidepressant agents $(\mathrm{N}=370)$

More than one third of prescriptions $(490,34.6 \%)$ were for TCAs and another third were for SSRIs $(455,32.1 \%)$. The most used single antidepressant was amitriptyline $(28.5 \%)$ followed by mirtazapine (19.9\%) and paroxetine (17.9\%). Monotherapy accounted for the majority of prescriptions (89.3\%). Venlafaxine and mirtazapine were the most common prescribed combination (16) followed by fluoxetine and mirtazapine (9) and amitriptyline and mirtazapine (6). There were no gender differences in the use of antidepressant drugs (Table 1). SSRIs, SNRIs and mirtazapine were mainly used for psychiatric conditions in $82.2 \%, 73.0 \%$ and $68.8 \%$ of the cases, respectively, while TCAs were mainly indicated $(63.7 \%)$ for non-psychiatric conditions such as headache and neuropathic pain. The most common psychiatric indication for use of antidepressant was depressive disorders $(381,26.9 \%)$ followed by anxiety disorders $(104,7.7 \%)$ and mixed anxiety and depressive disorders $(88,6.2 \%)$. Other indications included obsessive compulsive disorders, social phobia and panic disorders (Table 2). Headache was the most common non-psychiatric indication for antidepressant drugs $(84,22.7 \%)$ followed by diabetes and hypertension-related neuro/nephropathy(59,15.9\%) and neuropathic pain $(54,14.6 \%)$ (Table 3$)$.

\section{Discussion}

In this retrospective evaluation of prescriptions at a tertiary hospital in Oman four main antidepressant groups were identified; TCAs (amitriptyline, imipramine, clomipramine), SSRIs (paroxetine, fluoxetine), SNRIs (venlafaxine, duloxetine) and the atypical antidepressant mirtazapine. Amitriptyline was the most (28.5\%) prescribed single agent among all antidepressant drugs in this study. However, it is use was mainly indicated for non-psychiatric conditions such as headache and neuropathy. The analgesic effect of TCAs in several chronic painful conditions is discussed in details in the literature [10-11]. SSRIs, on the other hand, were the most common group $(125,32.8 \%)$ used for the treatment of depression followed by mirtazapine $(113,29.7 \%)$ (Table 2). This result is compatible with most clinical guidelines for treatment of depression and similar to utilization studies conducted in some developed countries [6,7,12-14]. Furthermore, the use of mirtazapine is increasing due its efficacy and safety over other classes especially in regards to sexual adverse effects [15]. Depressive disorders, anxiety disorders and mixed anxiety and depressive disorders were the most common indications for antidepressant use, accounting for $40.8 \%$ of the total prescriptions. This finding is also similar to other studies conducted elsewhere [12-14,16-18]. Antidepressants were prescribed more in females than in males, a finding that is similar to what is observed in some Western countries [12-14]. The age distribution showed that most of the patients $(47.8 \%)$ lie in the age group $30-50$ years of age. This is consistent with other global findings [12-16]. However, in the East Asia the majority of prescriptions were for those older than 40 years of age [18].

Like other studies, monotherapy was the preferred mode of therapy in our population [11-17]. The majority of prescriptions (89.3\%) were for a single antidepressant drug. This finding is reassuring as there is little evidence on the efficacy of combining antidepressant agents. 
Among polytherapy, venlafaxine and mirtazapine were the most prescribed drug combinations. They accounted for $16(21.4 \%)$ of combinations followed by fluoxetine and mirtazapine for 9 patients.

\section{Limitations}

Because of the retrospective nature of this analysis, the study has several limitations. For example the study does not address patient outcomes. Correlation of several demographic characteristics and drug therapy or dosage regimen were not possible due to lack of data. Finally, extending the results of this study to all country cannot be made with confidence as the utilization of antidepressants at this tertiary hospital might not represent all Oman.

\section{Conclusion}

Psychiatric conditions are the main indications for the use of antidepressants in our population. SSRIs, SNRIs and mirtazapine are the most used drugs for such purpose while TCAs were mainly used for non-psychiatric disorders. Monotherapy was the main mode of therapy employed by our physicians.

\section{Declaration}

The authors declare that they have no conflict of interest to disclose. We confirm that we have read the journal position on issues involved in ethical publication and affirm that this report is consistent with these guidelines.

\section{References}

1. Paykel ES, Brugha T, Fryers T (2005) Size and burden of depressive disorders in Europe. Eur Neuro psychopharmacol 15: 411-23.

2. Murray CJ, Lopez AD (1997) Alternative projections of mortality and disability by cause 1990-2020: Global Burden of Disease Study. Lancet 24: 1498-504.

3. World Health Organization (2008) Mental Health System in Oman. Electronic version.

4. Dejesus RS, Angstman KB, Cha SS, Williams MD (2013) Antidepressant Medication Use among Patients with Depression: Comparison between Usual Care and Collaborative Care Using Care Managers. Clin Pract Epidemiol Ment Health 9: 84-7.
5. Sobocki P, Ekman M, Agren H, Runeson B, Jönsson B (2006) the mission is remission: health economic consequences of achieving full remission with antidepressant treatment for depression. Int J ClinPract 60: 791-8.

6. Gardarsdottir H, Heerdink ER, van Dijk L, Egberts AC (2007) Indications for antidepressant drug prescribing in general practice in the Netherlands. J Affect Disord 98: 109-15.

7. Kendrick T, Peveler R (2010) Guidelines for the management of depression: NICE work? Br J Psychiatry 197: 345-7.

8. Olfson M, Marcus SC (2009) National patterns in antidepressant medication treatment. Arch Gen Psychiatry Aug 66: 848-56.

9. American Psychiatric Association: Diagnostic and Statistical Manual of Mental Disorders, 5th edition. 2013; Arlington, VA, American Psychiatric Publishing.

10. Watson CP, Evans RJ, Reed K, Merskey H, Goldsmith L, et al. (1982) Amitriptyline versus placebo in postherpetic neuralgia. Neurology 32: 671-3.

11. Häuser W, Wolfe F, Tölle T, Uçeyler N, Sommer C (2012) The role of antidepressants in the management of fibromyalgia syndrome: a systematic review and meta-analysis. CNS Drugs 1: 297-307.

12. Percudani M, Barbui C, Fortino I, Petrovich L (2004) Antidepressant drug use in Lombardy, Italy: a population-based study. J Affect Disord 83: 169-75.

13. Beck CA, Patten SB, Williams JV, Wang JL, Currie SR, et al. (2005) Antidepressant utilization in Canada.Soc Psychiatry PsychiatrEpidemiol 40: 799-807.

14. Bauer M, Monz BU, Montejo AL, Quail D, Dantchev N, et al. (2008) Prescribing patterns of antidepressants in Europe: results from the Factors Influencing Depression Endpoints Research (FINDER) study. Eur Psychiatry 23: 66-73.

15. Zetin M, Hoepner CT, Bjornson L (2006) Rational antidepressant selection: applying evidence-based medicine to complex real-world patients. Psychopharmacol Bull 39: 38-104.

16. Trivedi JK, Dhyani M, Sareen H, Yadav VS, Rai SB (2010) Antidepressant drug prescription pattern for depression at a tertiary health care center of Northern India. Med Pract Rev 1: 16-18.

17. Amuthaganesh M, Suhasinee S. Mathialagan S (2009) Pattern of antidepressant utilization at a tertiary hospital in Malaysia. Asian J Pharm Clin Res 5: 43-46.

18. Uchida N,Chong MY,Tan CH,Nagai H,Tanaka M,et al. (2007) International study on antidepressant prescription pattern at 20 teaching hospitals and major psychiatric institutions in East Asia: Analysis of 1898 cases from China, Japan, Korea, Singapore and Taiwan. Psychiatry Clin Neurosci 61: 522-8. 